\title{
Behaviour-dependent predation risk in swimming zooplankters
}

Marco Uttieri ${ }^{1^{*}}$, Daniela Cianelli ${ }^{1,2}$ and Enrico Zambianchi ${ }^{1}$

\begin{abstract}
Background: The survival of zooplanktonic organisms is determined by their capability of moving in a fluid environment, trading off between the necessities of finding prey and avoiding predators. In previous numerical experiments, we concentrated on the relationship between natatorial modality and encounter success of a virtual copepod swimming in the presence of prey distributed either in patches or uniformly in the environment.

Results: In this contribution, we extend this simulation framework to the encounter with chaetognaths, the primary copepod predators, considering different motion rules as a proxy of different swimming strategies and looking at the influence of the concentration of predators and the size of their detection radius in posing a risk on copepod survival. The outcomes of our simulations indicate that more convoluted trajectories are more vulnerable to predator encounter while straighter motions reduce predation risk.
\end{abstract}

Conclusions: Our results are then complemented with those obtained in our previous studies to perform a general cost-benefit analysis of zooplankton motion.

Keywords: Swimming; Predator-prey interactions; Zooplankton; Chaetognaths; Individual-based model

\section{Background}

Movement behaviour is a central theme in assessing the ecological role of an animal and its adaptations to the environment, with effects propagating up to the population and metapopulation levels (Tilman and Kareiva 1997; Begon et al. 2006). Individual motion responds to the necessity of finding food resources (Bell 1991), but at the same time it has evolutionarily adapted to reduce predation risks (Lima and Dill 1990). In aquatic systems, pelagic zooplankters provide the link between the primary producers and the higher trophic levels (e.g. fish and whales). Copepods are the primary grazers of phytoplankton (Marshall 1973; Turner 2004), but meanwhile they are also the main food resource for chaetognaths (Feigenbaum and Maris 1984). These latter predators rank second in terms of abundance in the zooplankton (Feigenbaum and Maris 1984), are considered as the chief carnivores of marine ecosystems (Reeve 1970) and are in

\footnotetext{
*Correspondence: marco.uttieri@uniparthenope.it

'Department of Sciences and Technologies, University of Naples

'Parthenope', Centro Direzionale di Napoli - Isola C4, Naples 80143, Italy

Full list of author information is available at the end of the article
}

turn prey for a variety of larger animals (as reviewed in Feigenbaum and Maris 1984). The interactions between copepods and chaetognaths are thus remarkably critical for a deep insight into the functioning of pelagic food webs and for the evaluation of the mechanisms underlying the flux of energy and matter among the components of the ecosystem.

Chaetognaths are ambush predators using the fans of hair present over their body surface as distance mechanoreceptors (Horridge and Boulton 1967). Mobile prey that, through a distinctive signal, elicit the sensory hairs are attacked: the chaetognath makes a bout with a rapid flick of the tail, the prey is blocked with the grasping spines and swallowed (Feigenbaum 1991). Adult copepods and copepodites are the main food resource of adult chaetognaths (Øresland 1987), while younger developmental stages may prefer copepod nauplii (Feigenbaum 1991); on occasion, cladocerans can become the mainstay of chaetognaths (Kehayias and Ntakou 2008; Kehayias and Kourouvakalis 2010).

Feigenbaum (1977) hypothesised that the movement pattern and the swimming speed of the prey might affect its predation risk. Such speculation is backed up by the

\section{实}

(c) 2013 Uttieri et al.; licensee Springer. This is an open access article distributed under the terms of the Creative Commons Attribution License (http://creativecommons.org/licenses/by/2.0), which permits unrestricted use, distribution, and reproduction in any medium, provided the original work is properly cited. 
evidence that male copepods are often preyed more extensively than the conspecific females (Acartia clausi, Alvarez-Cadena 1993; Paracalanus parvus, Saito and Kiørboe 2001). In fact, male copepods usually swim faster and over more tortuous paths (e.g. Doall et al. 1998; Weissburg et al. 1998; Nihongi et al. 2004; Uttieri et al. 2007b; Seuront 2011), peculiarities that may increase the possibility of entering the perceptive field of a predator, making them more vulnerable to predation.

Individual-based models (IBMs) are useful tools for addressing ecological questions, and they have proven to be successful in representing zooplankton motion (see Cianelli et al. 2012, for a recent review on this topic). The central actor of an IBM is the individual as unique component of the system, creating a population of individuals each with specific properties (Uchmański and Grimm 1996). Using a 'bottom-up' approach (Souissi et al. 2005), IBMs depict population-level emergent properties as the result of interactions between the individuals and their environment (Railsback 2001). In previous works (Uttieri et al. 2007a; Cianelli et al. 2009), model simulations have been carried out to evaluate how different search strategies, numerically represented by diverse typologies of random walks, may result in motion-specific encounters with uniformly (Uttieri et al. 2007a) and patchily (Cianelli et al. 2009) distributed prey. Here we expand upon these previous studies by addressing the problem of the encounter with a chaetognath predator. The present model aims at describing the encounter rate between a swimming copepod and an ambush chaetognath by relating the motion behaviour of a virtual copepod with the risk of entering the perceptive field of a chaetognath. The IBM explicitly accounted for realistic behavioural dynamics in the swimming motion of copepods and predators' perceptive field. In addition, to better evaluate the encounter probabilities, the model also considered the role of predator abundance in shaping predation risk. These aspects are of peculiar importance to understand the natatorial adaptations evolved by copepods to trade-off between encounter of food items and risk of being preyed upon. For comparative purposes, our simulations were complimentary compared with the encounter rates predicted by the theoretical model of Gerritsen and Strickler (1977), which explicitly accounts for the speed of both predators and prey, the encounter radius of the predator and the abundance of prey, but without considering the convolution of prey swimming tracks and the abundance of predators, which are instead realistically included in our simulations. This study constructs a comprehensive picture of the pros and cons linked to the different behavioural tactics employed by swimming copepods, and it is germane to a more exhaustive description of the predator-prey interactions in aquatic ecosystems.

\section{Methods}

\section{Individual-based model}

The IBM implemented in the present study presented two virtual entities: a swimming copepod and a still chaetognath. The former was allowed to move in a three-dimensional domain, while the latter was still according to its ambush strategy. The copepod was consequently characterised by two state variables: spatial coordinates (owing to its own movement, changing at each time step) and the number of predators encountered $P_{\mathrm{E}}$ (if, during the motion, it entered the perceptive field of the chaetognath). For the chaetognath, two state variables were defined as well: prey encounter (not calculated as homologous to $P_{\mathrm{E}}$ ) and the detection radius $R$. All these state variables could be considered additive components, as defined in Thygesen et al. (2007). As the movement of the copepod and its interactions with a predator were considered, the model could also be assumed as a spatially explicit IBM sensu Berec (2002).

In Uttieri et al. (2007a) and Cianelli et al. (2009), the model was run considering virtual spatial and temporal units (vsu and vtu, respectively). For the sake of clarity and with the purpose of making direct comparisons with earlier results, in this study we considered $1 \mathrm{vsu} \equiv 1 \mathrm{~mm}$ and $1 \mathrm{vtu} \equiv 1 \mathrm{~s}$; thus, the units will be interchangeably adopted throughout the text. The simulation frame was, as in Uttieri et al. (2007a) and Cianelli et al. (2009), a cubic field of $500 \mathrm{vsu}$ of side length, corresponding to a domain volume $V_{\mathrm{d}}=0.125 \mathrm{~m}^{3}$. A semi-absorbing condition was set at the boundaries (Uttieri et al. 2007a; Cianelli et al. 2009).

\section{Copepod swimming behaviour}

Following the numerical approach used in Uttieri et al. (2007a) and in Cianelli et al. (2009), five different threedimensional swimming behaviour representative of diverse copepod natatorial strategies were modelled in terms of random walks. Pure random walks (PRWs) have been traditionally used to simulate animal motion as a diffusive process (e.g. Okubo 1980). In our simulations, PRWs were generated following Zambianchi and Griffa (1994) as

$$
d x_{(i, t)}=m_{i} d \eta_{(i, t)}
$$

according to which the displacement at time $t$ along the direction $i$ ( $i=1,2$ or 3 , respectively, for $x, y$ and $z$ ) was due to a random impulse $d \eta_{(i, t)}$ extracted from a normal distribution with zero mean and second-order momentum $\left\langle d \eta_{(i, t)} \cdot d \eta_{(i, t)}\right\rangle=2 d t$ multiplied by a diffusion coefficient $m_{i}=1$.

A second typology of motion was modelled as a selfavoiding random walk (SARW), a movement strategy according to which a position in the domain can be 
occupied only once (Orr 1947). Numerically, SARWs were generated using Equation 1 with the proviso of avoiding the re-occupancy of the same point. At each time step, the instantaneous position was compared with the previous ones; if the point had already been visited, the position was calculated again. To reduce the limitations imposed by a discretised environment, at each reiteration the walker could move into one of adjacent neighbouring cubic subdomains but not into that occupied previously. For more details on the implementations of SARW, the interested reader can refer to Uttieri et al. (2007a).

The movement of virtual copepods was also modelled as a correlated random walk (CRW), according to which the motion at a generic time step was dependent on previous moves (Chandrasekhar 1943). This type of movement has been often reported in nature (e.g. Kareiva and Shigesada 1983; Codling and Hill 2005), and hence represents a more realistic description of animal behaviour than PRW. Numerically, CRW were simulated following the equation (Zambianchi and Griffa 1994)

$$
d u_{(i, t)}=-\frac{1}{T} u_{(i, t-1)} d t+m_{i} d \eta_{(i, t)}
$$

The velocity at each time step $t$ was due to a random impulse (similarly to PRW), plus the inclusion of a term $T$ (integral time scale; Kundu 1990) representing the memory of the process. Increasing $T$ values brought to more correlated, less tortuous walks. In our work, we used three $T$ values (CRW-T5, 5 time steps; CRW-T50, 50 time steps; CRW-T100, 100 time steps) to account for different memories in the motion.

Fifteen tracks for each class of motion were generated, each consisting of 50,000 points. At the beginning of each simulation $\left(t_{0}\right)$, the copepod was allowed to start its track from any random position inside the domain. In each run, the motion of only one copepod at time was modelled, so as to avoid any copepod-copepod interference. Fractal and multifractal properties of zooplankton motion can be extremely useful in depicting specific features of the swimming behaviour of these organisms (e.g., Seuront et al. 2004a, b). As a proxy of track convolution, the three-dimensional fractal dimension $D_{3 \mathrm{D}}$ (Uttieri et al. 2005) was evaluated for each trajectory through a box-counting approach (for further details on the methodologies, please refer to Uttieri et al. 2005 and Uttieri and Zambianchi 2012).

Swimming tracks were also analysed by calculating their speed $V(\mathrm{vsu} / \mathrm{vtu})$ as

$$
V_{t}=\frac{\left\|X_{t+1}-X_{t}\right\|}{\Delta t}
$$

where $X_{t+1}$ was the three-dimensional position of the virtual copepod at time $t+1$, and $\Delta t$ was the integration time step $(\Delta \mathrm{t}=1 \mathrm{vtu})$. To reconstruct more realistically the motion behaviour of copepods, our conceptual model contemplated an exponential increase of swimming speed as a function of $D_{3 D}$, i.e. more tortuous tracks were described at the cost of higher swimming speed. Such an assumption was based on the evidence that zooplanktonic organisms often describe paths with higher fractal dimension by swimming faster, as demonstrated for both copepods (e.g. Uttieri et al. 2007b; Seuront 2006, 2011) and cladocerans (e.g. Ziarek et al. 2011).

\section{Chaetognath abundance and perceptive field}

Chaetognaths are typically present all year round, with abundances of approximately $7-10$ ind. $\mathrm{m}^{-3}$ (e.g. Marazzo and Noguiera 1996; Daponte et al. 2004; Kehayias and Ntakou 2008). During peak periods, however, these abundances can rise three to ten times than the annual means (in the range of 30-40 ind. $\mathrm{m}^{-3}$; e.g. Daponte et al. 2004; Kehayias and Ntakou 2008; Noblezada and Campos 2008; Coston-Clements et al. 2009). Occasionally, exceptionally high abundances have been reported with more than 60 ind. $\mathrm{m}^{-3}$ (e.g. Daponte et al. 2004, 2011); it is noteworthy the maximum values of 134 ind. $\mathrm{m}^{-3}$ reported by Marazzo and Nogueira (1996) in Brazil and of 197.3 ind. $\mathrm{m}^{-3}$ scored by Noblezada and Campos (2012) in the Philippines. With the aim of reconstructing realistic conditions, in our model we consequently simulated three different abundances, each resembling a naturally occurring setting: a typical yearround abundance of approximately 10 ind. $\mathrm{m}^{-3}$, a peak value of approximately 40 ind. $\mathrm{m}^{-3}$ and a limit case of approximately 140 ind. $\mathrm{m}^{-3}$, which in our model domain respectively scaled as $1\left(C_{1}\right), 5\left(C_{2}\right)$ and 17 $\left(C_{3}\right)$ ind. $V_{d}^{-1}$ (Table 1).

Chaetognaths use their mechanoreceptors to remotely detect and locate a prey (Feigenbaum and Reeve 1977). Several authors (Horridge and Boulton 1967; Feigenbaum 1977; Feigenbaum and Reeve 1977; Nishii 1998) reported attack to probes vibrating at low frequency $(<500 \mathrm{~Hz})$ at a short distance $(<3 \mathrm{~mm})$ from the chaetognath's head, while probes moving in proximity of the tail elicited an escape or no reaction at all (Feigenbaum and Maris 1984). Parry

Table 1 Abundances of chaetognaths used in the simulations and equivalent in situ values derived from literature

\begin{tabular}{lll}
\hline \multicolumn{3}{c}{ Chaetognath abundance } \\
\hline Model & Equivalent to \\
\hline$C_{1}$ & 1 ind. $V_{d}^{-1}$ & $\begin{array}{l}\text { Approximately } 10 \text { ind. } \mathrm{m}^{-3} \text { (typical year-round } \\
\text { abundance) }\end{array}$ \\
$C_{2} \quad 5$ ind. $V_{d}^{-1}$ & $\begin{array}{l}\text { Approximately } 40 \text { ind. } \mathrm{m}^{-3} \text { (typical of peak periods) } \\
C_{3}\end{array} \quad 17$ ind. $V_{d}^{-1}$ & $\begin{array}{l}\text { Approximately } 140 \mathrm{ind} . \mathrm{m}^{-3} \text { (limit case of excess } \\
\text { abundance) }\end{array}$ \\
\hline
\end{tabular}


(1944) also observed an attack when the probe was positioned above the head of the chaetognath. On the basis of these observations, in our simulations we empirically considered a generic ambush pelagic chaetognath with a spherical perceptive field centred on its head. To account for the effect of the extension of this encounter volume, we adopted three values of the detection radius $R$ (Table 2). Based on vibrating probe experiments, we set $R_{1}=1 \mathrm{~mm}$ (Horridge and Boulton 1967) and $R_{2}=3 \mathrm{~mm}$ (Feigenbaum and Reeve 1977). We then considered the limit case of $R_{3}=10 \mathrm{~mm}$ following the calculations by Saito and Kiørboe (2001).

The distribution of predators was determined stochastically by assigning a random position to the chaetognath. To account for the extension of the detection radius $R$, all individuals were always placed at a minimum distance of $10 \mathrm{~mm}$ from the boundaries.

\section{Predator encounter}

The interaction between the copepod and the chaetognath was considered as the entrance of the copepod in the perceptive field of the predator $\left(P_{\mathrm{E}}\right.$; Figure 1$)$. Based on the components of predation (Holling 1966), Gerritsen and Strickler (1977) postulated that the interaction between a predator and its prey is the result of four concatenated events (encounter, recognition, capture and ingestion). In our IBM, $P_{\mathrm{E}}$ specifically represented the encounter between a predator and a prey, without considering the following steps of the chain of events (e.g. capture). Numerically, at each time step, the copepod swam according to one of the movement rules detailed above. If the position of the copepod was inside the perceptive field of the chaetognath (Figure 1), an encounter with the predator $P_{\mathrm{E}}$ was scored. To build a statistically comparable data set, all tracks were run to complete a 50,000-step long walk; for this reason, even after running into the perceptive field of a chaetognath, the copepod could continue swimming until the end of the simulation. Every single predator-prey interaction could be counted only once, so no multiple encounters between the same copepod and the same chaetognath could be recorded. The IBM did not include any escape response by the copepod nor any feeding bout of the chaetognath. $P_{\mathrm{E}}$ was then related to $D_{3 \mathrm{D}}$ and $V$ in order to investigate the dependency on path tortuosity and

Table 2 Values of detection radius $\boldsymbol{R}$ used in the simulations as derived from experimental results

\begin{tabular}{lc}
\hline Detection radius $\boldsymbol{R}$ & Value \\
\hline$R_{1}$ & $1 \mathrm{~mm}$ (Horridge and Boulton 1967) \\
$R_{2}$ & $3 \mathrm{~mm}$ (Feigenbaum and Reeve 1977) \\
$R_{3}$ & $10 \mathrm{~mm}$ (Saito and Kiørboe 2001) \\
\hline
\end{tabular}

swimming speed, respectively. A synthetic flowchart of the model is presented in Figure 2.

Classically, in the field of plankton ecology, the encounter rate $Z_{P}$ between two organisms has been modelled as (Gerritsen and Strickler 1977)

$$
Z_{P}=\left\{\begin{array}{l}
\frac{\pi R^{2} N_{H}}{3}\left(\frac{\bar{u}^{2}+3 v^{2}}{v}\right) \text { for } v \geq \bar{u} \\
\frac{\pi R^{2} N_{H}}{3}\left(\frac{v^{2}+3 \bar{u}^{2}}{\bar{u}}\right) \text { for } \bar{u} \geq v
\end{array}\right.
$$

where $R$ is predator's encounter radius and $N_{H}$ is the density of prey, whereas $\bar{u}$ and $v$ are respectively the mean prey and predator speeds. To further appreciate the importance of track convolution in determining the effective risk of predator encounter, we also computed $Z_{P}$ considering an ambush predator $(v=0)$ with one prey at time $\left(N_{H}=1\right)$ for the different $R$ values $\left(R_{1}, R_{2}\right.$ and $R_{3}$ ) used in the simulations and compared it to the $P_{\mathrm{E}}$ resulting from our IBM. It is worth stressing that, since the model by Gerritsen and Strickler (1977) does not explicitly include predator abundance, we compared the trends in $Z_{P}$ and $P_{\mathrm{E}}$ in dependence of motion speed for $C_{1}$ case only.

\section{Statistical analyses}

$P_{\mathrm{E}}, D_{3 \mathrm{D}}$ and $V$ values were statistically analysed with one-way analysis of variance (ANOVA) (Zar 1984). In particular, the statistical test was performed to evaluate any significant difference between the same class of motion under different conditions (i.e. different predator abundances and perceptive distances) and between the five motion strategies in the same simulation scenario. ANOVA was corroborated by a post hoc multiple comparison test using Tukey's honestly significant difference method (Hochberg and Tamhane 1987), a single-step procedure using the studentised range statistic to compare all pairs of means.

\section{Results and discussion \\ Results}

The tracks belonging to the five classes of motion simulated were differentiated on the basis of their $D_{3 \mathrm{D}}$ values (ANOVA: $p<1 \times 10^{-5}, n=75$ ). PRW and SARW scored the highest values, indicative of tracks spreading in the domain, while increasing memory in the motion resulted in straighter tracks (Table 3). Following the phenomenologically based approach discussed in the previous section, PRW and SARW were described at statistically higher speed than CRWs (ANOVA: $p<1 \times 10^{-5}, n=75$ ), increasing exponentially with $D_{3 \mathrm{D}}\left(r^{2}>0.99\right)$ (Figure 3). This intrinsic behaviour thus allowed the analysis of the concomitant effect of speed and fractal dimension on the encounter rate, mimicking realistic zooplankton 


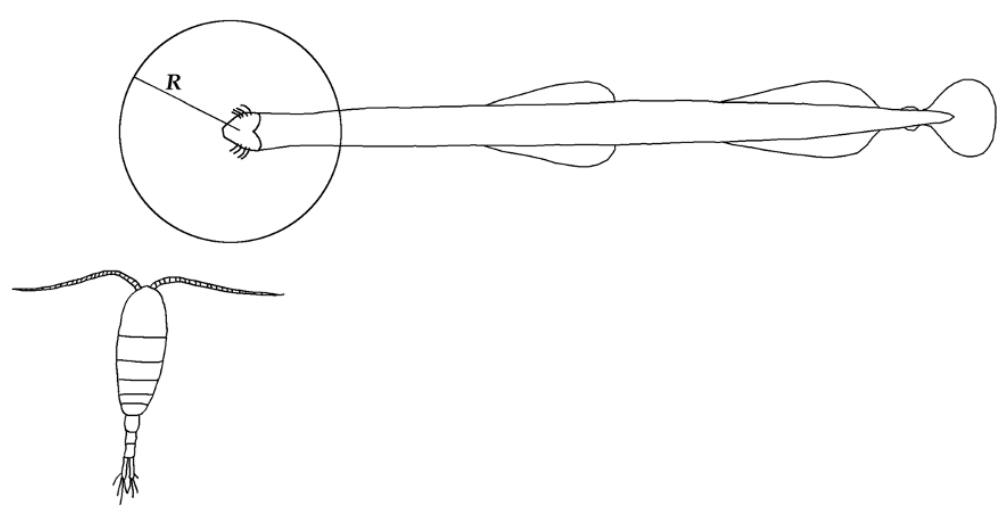

Figure 1 Encounter process between the virtual swimming copepod and a predator chaetognath. The model accounts for different natatorial modes; the realistic reconstruction of the perceptive field of the chaetognath is based upon available literature evidence (elements not in scale).

swimming modes characterised by an increase of motion speed together with track convolution (e.g. Uttieri et al. 2007b; Seuront 2006, 2011; Ziarek et al. 2011).

Expectedly, for each class of motion $P_{\mathrm{E}}$ increased as the perceptive radius $R$ augmented for any given predator abundance $C$; similarly, $P_{\mathrm{E}}$ augmented also as a function of the number of chaetognaths independently of the $R$ considered. Generally, the same class of motion did not show significant differences at low $C$ and with short $R$, whereas in the presence of a higher number of chaetognaths and/or of longer detection radii the dissimilarities were more pronounced. Only CRW-T50 and CRWT100 showed a reduced difference even with high $C$ and $R$ values.

A general trend showed that $P_{\mathrm{E}}$ increased exponentially as a function of $D_{3 \mathrm{D}}$ independent of the $C$ and $R$ tested (Figure 4; Table 4), while a linear dependence with speed was recognisable (Figure 5 ; Table 4 ). The only exceptions to such general rule were $C_{1} R_{1}$ for $D_{3 \mathrm{D}}$ (linear increase) and $C_{1} R_{3}$ for $V$ (exponential increase). These results could be summarised as

$$
\begin{aligned}
& P_{E} \propto \beta D_{3 D} \\
& P_{E} \propto \gamma \mathrm{V}
\end{aligned}
$$

with

$$
\beta=f(C, R) \text { and } \gamma=f(C, R)
$$

representing multiplicative factors dependent on the abundance and perceptive radius of the predator chaetognath, in a fashion similar to what derived for the encounter with prey discussed in Uttieri et al. (2007a) and Cianelli et al. (2009). At low predator abundances and in the presence of short detection radii, all five classes of motion displayed similar $P_{\mathrm{E}}$ values, without relevant differences in the predation risk. By contrast, when the number of predators increased and when their perceptive distance was larger, PRW and SARW were more vulnerable to predators than CRWs. The dependence of $P_{\mathrm{E}}$ on $D_{3 \mathrm{D}}$ and $V$ was more robust at $C_{2}$ and $C_{3}$ rather than at $C_{1}$, independently of the $R$ value (Table 4); this result supported the evidence that for low $C$ (and for short $R$ ) no remarkable difference between the movement behaviour simulated was appreciable.

The theoretical encounter rate $Z_{P}$ between our virtual copepod and chaetognath sensu Gerritsen and Strickler (1977) was evaluated following Equation 4. Considering only the $C 1$ case owing to the limitations imposed by such model detailed above, an exponential increase in $Z_{P}$ with speed was noticed. This result contrasts with our simulations, which instead recorded a linear relationship between $P_{\mathrm{E}}$ and $V$, pointing out that theoretical models based on speed as the only behavioural component do not adequately reconstruct the encounter process.

\section{Discussion}

Predation is a major selective force in ecological systems (Barbosa and Castellanos 2005). Predation risk increases with dispersal, and dispersing animals reduce such a risk by adopting specific behavioural options (Zollner and Lima 2005, and references therein). The interactions between copepods and chaetognaths occupy a central position in the structure of pelagic food webs, governing the interaction between the lower and upper trophic levels (Reeve 1970). In this study, we reconstructed the motion of a virtual swimming copepod using five classes of random walks, simulating different modalities of exploration of the environment (Uttieri et al. 2007a; Cianelli et al. 2009). In particular, our simulations explicitly accounted for the empirically verified phenomenon of concomitant increase of swimming speed and fractal dimension in copepod swimming motion with the intention of mimicking 


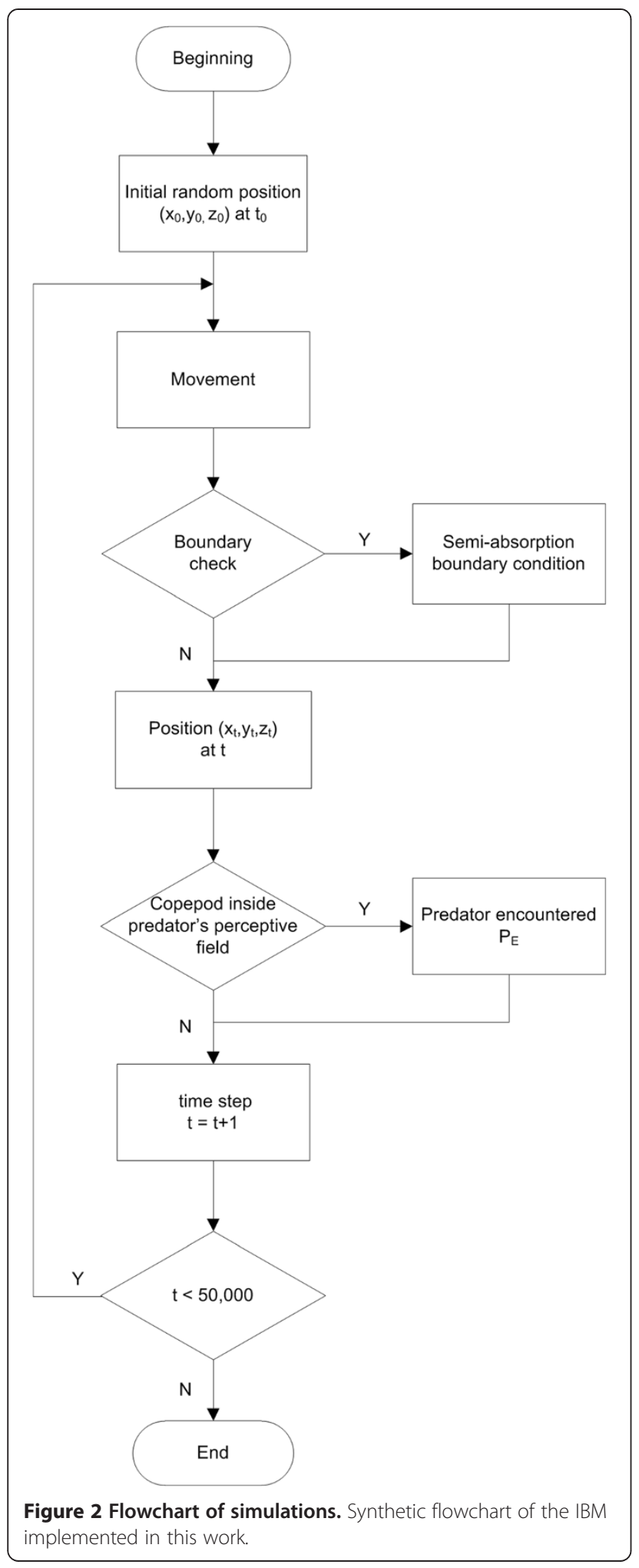

a more realistic behaviour. Practical numerical limitations, however, hampered us from running the entire gamut of possible motion patterns, such as Lévy walks (Bartumeus et al. 2005) and biased random walks (Codling and
Table 3 Mean ( \pm standard deviation) $D_{3 \mathrm{D}}$ and swimming speed $V$ (vsu/vtu) values of the simulated behaviour

\begin{tabular}{lcc}
\hline & $\mathbf{D}_{\text {3D }}$ & $\boldsymbol{V}$ (vsu/vsu) \\
\hline PRW & $1.923 \pm 0.087$ & $1.126 \pm 0.002$ \\
SARW & $1.942 \pm 0.084$ & $1.348 \pm 0.002$ \\
CRW-T5 & $1.765 \pm 0.089$ & $0.501 \pm 0.002$ \\
CRW-T50 & $1.559 \pm 0.075$ & $0.157 \pm 0.003$ \\
CRW-T100 & $1.520 \pm 0.080$ & $0.111 \pm 0.003$ \\
\hline
\end{tabular}

Hill 2005), which might be included in future model implementations. We therefore deliberately focused on a subset of the possible movement rules (PRW, SARW and CRWs) which, on previous evidences, were adequate to represent zooplankton motion.

The virtual copepod was allowed to swim in the presence of a chaetognath, recreating several possible realistic conditions of predator abundance and perceptive field. Overall, the simulations showed that the predation risk $P_{\mathrm{E}}$ increased with the tortuosity (evaluated in terms of $\mathrm{D}_{3 \mathrm{D}}$ ) and the speed of copepod motion. This effect was more noticeable at high predator abundances and when considering large detection radii, as postulated in the theoretical model by Gerritsen and Strickler (1977). In addition, our results confirm the conjectures by Feigenbaum (1977), Duró and Saiz (2000) and Saito and Kiørboe (2001) who hypothesised that prey swimming behaviour might influence the predation by chaetognaths. The evidence that more conspicuous motion (i.e. motion with higher $D_{3 \mathrm{D}}$ ) is susceptible to higher predation risk provides a rationale for the observation that male copepods, which usually swim faster and describe tracks with higher $\mathrm{D}_{3 \mathrm{D}}$ than conspecific females, are preyed more intensely by chaetognaths (Alvarez-Cadena 1993; Saito and Kiørboe 2001).

The mechanistic encounter model here implemented incorporates both prey behaviour (copepod swimming modes) and predator perception (chaetognath perceptive field). Our simulations elucidate a linear dependence of $P_{\mathrm{E}}$ with $V$ in place of the exponential increase predicted by the theoretical model of Gerritsen and Strickler (1977). Such a discrepancy buttresses that speed only is not an exhaustive behavioural descriptor of the encounter process, but the complexity of the motion must be integrated to gain a more comprehensive view. It should be emphasised that our model intrinsically included also the effect of $D_{3 \mathrm{D}}$, which cannot be incorporated explicitly in Equation 4, but which nonetheless empirically affects the encounter rate between planktonic organisms as demonstrated by our model results.

The perceptive radii $R$ used in our simulations have been based upon indirect measurements available in the literature (as summarised in Table 2). It is expected that specifically conceived laboratory experiments may help 


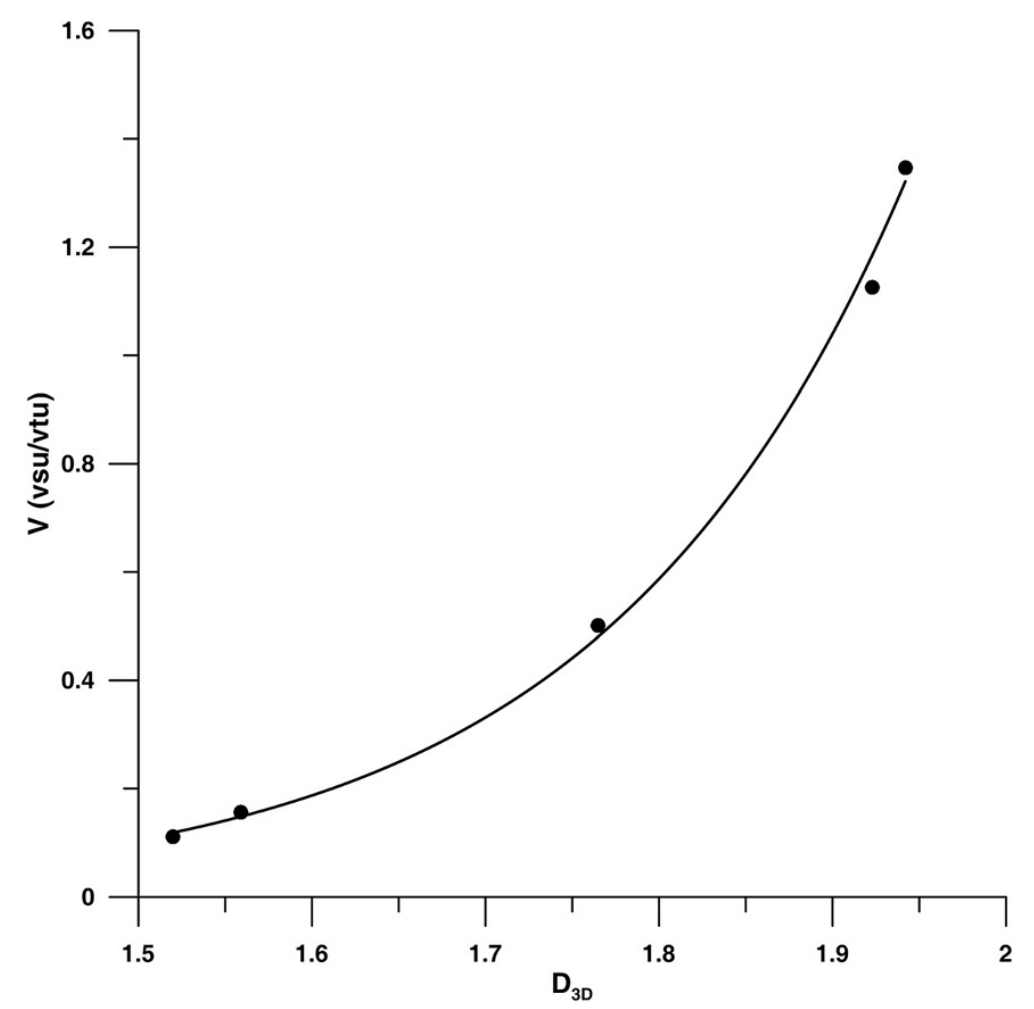

Figure 3 Relationship between $D_{3 D}$ and $V$. Exponential increase in the swimming speed $V$ as a function of the three-dimensional fractal dimension $D_{3 \mathrm{D}}$.

obtaining direct estimates of chaetognath reactive distances, which could be integrated in next model versions. Such information, together with the simulation of realistic copepod species-specific movement behaviour (as, for example, done in Uttieri et al. 2010, for Clausocalanus furcatus and Oithona plumifera), would provide a window of insight into the phenomenon of encounter risk in zooplankton organisms.

The outcomes of the present set of simulations can be integrated with previous models exploring the encounter efficiency of the chosen classes of motion at finding prey items $\left(E_{R}\right)$ in uniform (Uttieri et al. 2007a) and patchy (Cianelli et al. 2009) distributions. These numerical runs highlighted that $E_{R} \propto \alpha D_{3 D}, \alpha=f\left(c_{m}, N_{H}\right)$ being a multiplicative factor dependent on motion complexity $\left(c_{\mathrm{m}}\right)$ and prey abundance $\left(N_{H}\right)$ (Cianelli et al. 2009). Such relationship is fundamentally the same relating $P_{\mathrm{E}}$ and $D_{3 \mathrm{D}}$ (Equation 5) and $P_{\mathrm{E}}$ and $V$ (Equation 6), indicating that both the encounter of predators $\left(P_{\mathrm{E}}\right)$ and of prey $\left(E_{\mathrm{R}}\right)$ are dependent on the tortuosity and on the speed of the motion. The complementation of these results can be used to define a cost-benefit analysis of zooplankton motion. Uncorrelated motions (PRW and SARW) turn out as not beneficial in an evolutionary perspective: while these movement rules guarantee high number of encounters of prey, they are also associated with a high predation risk.
On the opposite extreme, motions with high correlation may reduce $P_{\mathrm{E}}$ but at the cost of low $E_{R}$. CRW-T5 seems to balance between these two opposite conditions, providing a trade-off between the different needs of copepods. This conclusion is supported by the Lagrangian characterisation of the swimming tracks of the marine copepod C. furcatus (Uttieri et al. 2008) and of the freshwater cladoceran Daphnia pulex (Uttieri et al. 2004), which both show the features of a moderately correlated random walk.

Several works have demonstrated that small-scale turbulence may influence the encounter rate between two planktonic organisms (Rothschild and Osborn 1988; Evans 1989; Lewis and Pedley 2000) by affecting the relative speeds of both prey and predator but without any direct effect on the subsequent processes (recognition, capture and ingestion). In addition, of peculiar relevance is also the duration of the contact between a plankter and its predator: for an encounter to determine a capture, the prey must reside inside the perceptive field of the marauder for a time long enough to elicit the attack (e.g. Lewis and Pedley 2000; Mariani et al. 2005, 2008). In our simulations, turbulence was deliberately excluded to avoid the addition of a further element of variability in the encounter process.

In the description of the model, we made some basic assumptions, but the conclusions thus derived have 

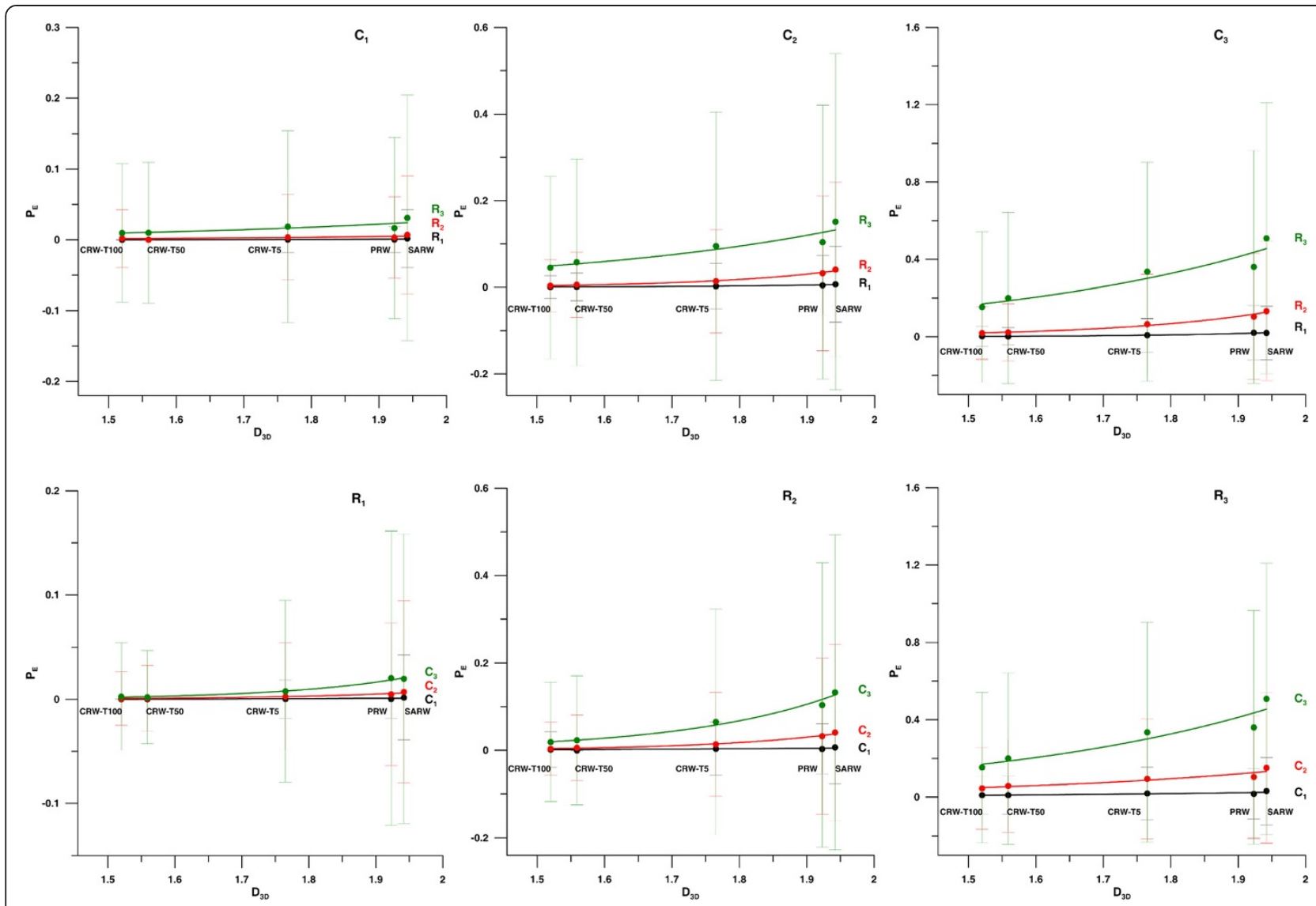

Figure 4 Relationship between $D_{3 D}$ and $P_{E}$. The number of encountered predators $P_{E}$ was plotted as a function of the three-dimensional fractal dimension $D_{3 D}$ of the swimming tracks, depending on the abundance and on the perceptive field of the modelled chaetognath. Vertical error bars indicate the variability of $P_{E}$ for each class of motion. The $r^{2}$ of the regression lines are reported in Table 4 .

some degree of adaptability to more general conditions. In our simulations, we considered a generic pelagic chaetognath. However, the main deductions on the role of predator abundance and perceptive radius can be applied also to the benthic genus Spadella, which shows an

Table $4 P_{E}$ vs $D_{3 \mathrm{D}}$ and $P_{\mathrm{E}}$ vs $V$

\begin{tabular}{llll}
\hline & $\boldsymbol{C}_{\mathbf{1}}$ & $\boldsymbol{C}_{\mathbf{2}}$ & $\boldsymbol{C}_{\mathbf{3}}$ \\
\hline$P_{\mathrm{E}}$ VS $D_{3 \mathrm{D}}$ & & & \\
$R_{1}$ & $0.51^{\mathrm{a}}$ & 0.98 & 0.97 \\
$R_{2}$ & 0.73 & 0.99 & 0.99 \\
$R_{3}$ & 0.80 & 0.92 & 0.92 \\
$P_{\mathrm{E}}$ VS $V$ & & & \\
$R_{1}$ & 0.65 & 0.97 & 0.97 \\
$R_{2}$ & 0.73 & 0.99 & 0.98 \\
$R_{3}$ & $0.78^{\mathrm{b}}$ & 0.88 & 0.88 \\
\hline
\end{tabular}

Coefficients of regressions $r^{2}$ of the fits shown in Figure 4 of the predation risk $P_{\mathrm{E}}$ as a function of track convolution $\left(D_{3 \mathrm{D}}\right)$ and in Figure 5 of $P_{\mathrm{E}}$ as a function of swimming speed $(V)$ in the different abundance $\left(C_{1}, C_{2}\right.$ and $\left.C_{3}\right)$ and predator detection radius $\left(R_{1}, R_{2}\right.$ and $\left.R_{3}\right)$. In the $P_{\mathrm{E}}$ vs $D_{3 \mathrm{D}}$ case, the regressions were exponential except for $C_{1} R_{1}$ ('best fit: linear), while in the $P_{\mathrm{E}} \mathrm{VS} V$ one they were linear with the exclusion of $C_{1} R_{3}$ ('best fit: exponential). attack behaviour similar to that of pelagic chaetognaths (Horridge and Boulton 1967). We also assumed a continuous swimming copepod as a prey, but other zooplankters can be important elements in the diet of chaetognaths as well (Feigenbaum and Maris 1984; Kehayias and Ntakou 2008). Our results can therefore be extended by considering the classes of motion analysed as different exploration strategies of a generic zooplanktonic organisms, such as cladocerans.

Copepods are well known for their ability to discriminate between hydrodynamic signals created by their own movement from that due to the motion of prey or predators (Hwang and Strickler 2001). This ability allows them to perform efficient escapes from an approaching predator, and they may use a 'fluid-dynamical camouflage' (Hwang and Strickler 2001) to reduce predation risk.

Copepods are staple food for both chaetognaths and fish larvae, which thus compete for the same resource (CostonClements et al. 2009). Petrik et al. (2009) implemented an IBM to investigate the foraging of haddock and cod larvae on copepods displaying species-specific escape reactions. 

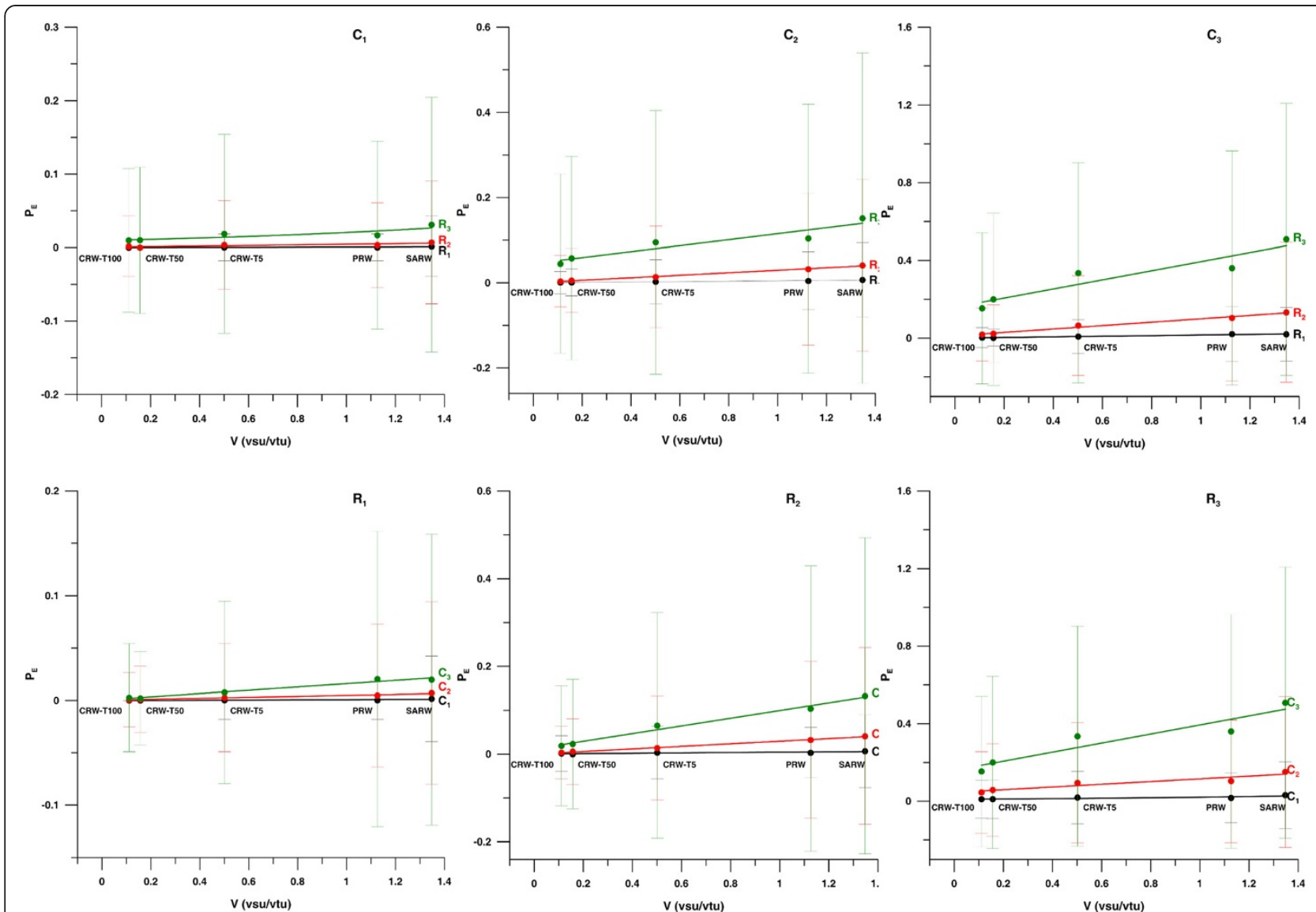

Figure 5 Relationship between $\mathbf{V}$ and $\mathbf{P}_{\mathbf{E}}$. The number of encountered predators $P_{\mathrm{E}}$ was plotted as a function of the swimming speed $V$ of the modelled tracks, depending on the abundance and on the perceptive field of the modelled chaetognath. Vertical error bars indicate the variability of $P_{E}$ for each class of motion. The $r^{2}$ of the regression lines are reported in Table 4.

Their results highlight that escape abilities are more crucial than encounter rate in determining the predation risk and thus represent an important selective determinant of prey selection by fish larvae. Future implementations of our model will include the realistic description of copepod movement and their escape behaviour with the aim of reconstructing more faithfully the interactions between copepods and chaetognaths.

\section{Conclusions}

The interactions between zooplanktonic organisms are mediated by their swimming behaviour. Pelagic copepods display a great variety of natatorial modes, used to exploit at best the environmental conditions encountered. At the same time, however, by moving in the environment, these organisms are subject to the encounter with predators. Swimming behaviour can thus be considered an ecological descriptor of the adaptations developed by individuals to proliferate.

Previous modelling simulations have concentrated on the swimming-dependent encounters with prey (Uttieri et al. 2007a; Cianelli et al. 2009). In this work, we extend this numerical framework to the process of predator encounter. The results demonstrate that more tortuous tracks are subject to higher predation risk and that the encounter with marauders is dependent on their abundance and perceptive field. In view of a cost-benefit analysis, uncorrelated and highly correlated motions result as not beneficial, as either determining an excessive predation risk (uncorrelated motions) or a too low number of encounters with prey (highly correlated walks). Motions with a low degree of correlation emerge as efficiently balancing the costs and benefits of predator and prey encounter and thus can be considered as an efficient search strategy. The results collected in the framework of the present investigation improve our understanding of the behavioural plasticity of zooplanktonic organisms.

\section{Competing interests}

The authors declare that they have no competing interests.

\section{Authors' contributions}

$\mathrm{MU}, \mathrm{DC}$ and EZ conceived of the study, interpreted the results and were involved in drafting the manuscript. MU and DC designed the numerical simulation. All authors read and approved the final manuscript. 


\section{Acknowledgements}

The research of Marco Uttieri was supported by the MOKA project (Modelling and Observation of zooplanKtonic orgAnisms; ID: RBFR10VF6M) financed by the Italian Ministry of Education, University and Research. Marco Uttieri is grateful to T. Kiørboe and G. Kehayias for sharing information on chaetognath biology and ecology and to M. Pottek for the design of the MOKA cartoon.

\section{Author details}

${ }^{1}$ Department of Sciences and Technologies, University of Naples 'Parthenope', Centro Direzionale di Napoli - Isola C4, Naples 80143, Italy. ${ }^{2}$ ISPRA - Institute for Environmental Research and Protection, Via Brancati 60, Rome 00166, Italy.

Received: 28 August 2013 Accepted: 25 September 2013 Published: 4 October 2013

\section{References}

Alvarez-Cadena JN (1993) Feeding of the chaetognath Sagitta elegans Verrill. Estuar Coast Shelf Sci 36(2):195-206

Barbosa P, Castellanos I (2005) Ecology of predator-prey interactions. Oxford University Press, New York

Bartumeus F, Da Luz MGE, Viswanathan GM, Catalan J (2005) Animal search strategies: a quantitative random-walk analysis. Ecology 86(11):3078-3087

Begon M, Townsend CR, Harper $J$ (2006) Ecology: from individuals to ecosystems. Blackwell Publishing Ltd., Malden

Bell WJ (1991) Searching behaviour. The behavioural ecology of finding resources. Chapman \& Hall, London

Berec $L$ (2002) Techniques of spatially explicit individual-based models: construction, simulation, and mean-field analysis. Ecol Model 150(1-2):55-81

Chandrasekhar S (1943) Stochastic problems in physics and astronomy. Rev Mod Phys 15(1):1-89

Cianelli D, Uttieri M, Strickler JR, Zambianchi E (2009) Zooplankton encounters in patchy particle distributions. Ecol Model 220(5):596-604

Cianelli D, Uttieri M, Zambianchi E (2012) Individual based modelling of planktonic organisms. In: Zhang W-J (ed) Ecological modeling. Nova Science Publishers, Inc., New York, pp 83-96

Codling EA, Hill NA (2005) Sampling rate effects on measurements of correlated and biased random walks. J Theor Biol 233(4):573-588

Coston-Clements L, Wagget RJ, Tester PA (2009) Chaetognaths of the United States South Atlantic Bight: distribution, abundance and potential interactions with newly spawned larval fish. J Exp Mar Biol Ecol 373(2):111-123

Daponte MC, Capitanio FL, Nahabedian DE, Viñas MD, Negri RM (2004) Sagitta friderici Ritter-Záhony (Chaetognatha) from South Atlantic waters: abundance, population structure, and life cycle. ICES J Mar Sci 61(4):680-686

Daponte MC, Calcagno JA, Acevedo-Luque MJJ, Martos P, Machinandiarena L, Esnal GB (2011) Composition, density, and biomass of Salpidae and Chaetognatha in the southwestern Atlantic Ocean (34.5 $\left.{ }^{\circ} \mathrm{S}-39^{\circ} \mathrm{S}\right)$. Bull Mar Sci 87(3):437-461

Doall MH, Colin SP, Strickler JR, Yen J (1998) Locating a mate in 3D: the case of Temora longicornis. Phil Trans R Soc London B 353:681-689

Duró A, Saiz E (2000) Distribution and trophic ecology of chaetognaths in the western Mediterranean in relation to an inshore-offshore gradient. J Plankton Res 22(2):339-361

Evans GT (1989) The encounter speed of moving predator and prey. J Plankton Res 11(2):415-417

Feigenbaum DL (1977) Nutritional ecology of the Chaetognatha with particular reference to external hair patterns, prey detection, and feeding. University of Miami, PhD thesis

Feigenbaum D (1991) Food and feeding behaviour. In: Bone Q, Kapp H, Pierrot-Bults AC (ed) The biology of chaetognaths. Oxford University Press, Oxford, pp 45-54

Feigenbaum D, Reeve MR (1977) Prey detection in the Chaetognatha: response to a vibrating probe and experimental determination of attack distance in large aquaria. Limnol Oceanogr 22(6):1052-1058

Feigenbaum DL, Maris RC (1984) Feeding in the Chaetognatha. In: Barnes M (ed) Oceanography and marine biology: an annual review, vol 22. Aberdeen University Press, Aberdeen, pp 343-392

Gerritsen J, Strickler JR (1977) Encounter probabilities and community structure in zooplankton: a mathematical model. J Fish Res Board Can 34:73-82
Hochberg Y, Tamhane AC (1987) Multiple comparison procedures. John Wiley \& Sons, Inc., New York

Holling CS (1966) The functional response of invertebrate predators to prey density. Mem Entomol Soc Can 48:1-86

Horridge GA, Boulton PS (1967) Prey detection by Chaetognatha via a vibration sense. Proc R Soc Lond B 168(1013):413-419

Hwang J-S, Strickler JR (2001) Can copepods differentiate prey from predator hydromechanically? Zool Stud 40(1):1-6

Kareiva PM, Shigesada N (1983) Analyzing insect movement as a correlated random walk. Oecologia 56:234-238

Kehayias G, Kourouvakalis D (2010) Diel vertical migration and feeding of chaetognaths in coastal waters of the eastern Mediterranean. Biologia 65(2):301-308

Kehayias G, Ntakou E (2008) Abundance, vertical distribution and feeding of chaetognaths in the upper $50 \mathrm{~m}$ layer of the eastern Aegean Sea. J Nat Hist 42(5-8):633-648

Kundu PJ (1990) Fluid mechanics. Academic Press, San Diego

Lewis DM, Pedley TJ (2000) Planktonic contact rates in homogeneous isotropic turbulence: theoretical predictions and kinematic simulations. J Theor Biol 205:377-408

Lima SL, Dill M (1990) Behavioral decisions made under the risk of predation: a review and prospectus. Can J Zool 68(4):619-640

Marazzo A, Nogueira CSR (1996) Composition, spatial and temporal variations of Chaetognatha in Guanabara Bay, Brazil. J Plankton Res 18(12):2367-2376

Mariani P, Botte V, Ribera d'Alcalà M (2005) An object-oriented model for the prediction of turbulence effects on plankton. Deep Sea Res II 52(9-10):1287-1307

Mariani P, Botte V, Ribera d'Alcalà M M (2008) A numerical investigation of the impact of turbulence on the feeding rates of Oithona davisae. J Mar Syst 70(3-4):273-286

Marshall SM (1973) Respiration and feeding in copepods. Adv Mar Biol 11:57-120

Nihongi A, Lovern SB, Strickler JR (2004) Mate-searching behaviors in the freshwater calanoid copepod Leptodiaptomus ashlandi. J Mar Syst 49(1-4):65-74

Nishii S (1998) Hydrodynamical perception of chaetognaths. Mie University, MSc thesis

Noblezada MMP, Campos WL (2008) Spatial distribution of chaetognaths off the northern Bicol Shelf. Philippines (Pacific coast) 65(3):484-494

Noblezada MMP, Campos WL (2012) Chaetognath assemblages along the Pacific Coast and adjacent inland waters of the Philippines: relative importance of oceanographic and biological factors. ICES J Mar Sci 69(3):410-420

Okubo A (1980) Diffusion and ecological problems: mathematical models. Springer, Berlin

Øresland V (1987) Feeding of the chaetognaths Sagitta elegans and S. setosa at different seasons in Gullmarsfjorden, Sweden. Mar Ecol Prog Ser 39:69-79

Orr WJC (1947) Statistical treatment of polymer solutions at infinite dilution. Trans Faraday Soc 43:12-27

Parry DA (1944) Structure and functioning of the gut in Spadella cephaloptera and Sagitta setosa. J Mar Biol Assoc UK 26(01):16-36

Petrik CM, Kristiansen T, Lough RG, Davis CD (2009) Prey selection by larval haddock and cod on copepods with species-specific behavior: an individual-based model analysis. Mar Ecol Prog Ser 396:123-143

Railsback SF (2001) Concepts from complex adaptive systems as a framework for individual-based modelling. Ecol Model 139(1):47-62

Reeve MR (1970) The biology of chaetognaths. I. Quantitative aspects of growth and egg reproduction in Sagitta hispida. In: Steele JH (ed) Marine food chains. Oliver \& Boyd, Edinburgh, pp 168-189

Rothschild BJ, Osborn TR (1988) Small-scale turbulence and plankton contact rates. J Plankton Res 10(3):465-474

Saito H, Kiørboe T (2001) Feeding rates in the chaetognath Sagitta elegans: effects of prey size, prey swimming behaviour and small-scale turbulence. J Plankton Res 23(12):1385-1398

Seuront $L$ (2006) Effect of salinity on the swimming behaviour of the estuarine calanoid copepod Eurytemora affinis. J Plankton Res 28(9):805-813

Seuront L (2011) Hydrocarbon contamination decreases mating success in a marine planktonic copepod. PLoS ONE 6(10):e26283

Seuront L, Schmitt FG, Brewer MC, Strickler JR, Souissi S (2004a) From random walk to multifractal random walk in zooplankton swimming behavior. Zool Stud 43(2):498-510

Seuront L, Yamazaki H, Souissi S (2004b) Hydrodynamic disturbance and zooplankton swimming behaviour. Zool Stud 43(2):376-387 
Souissi S, Seuront L, Schmitt FG, Ginot V (2005) Describing space-time patterns in aquatic ecology using IBMs and scaling and multi-scaling approaches. Nonlinear Anal-Real 6(4):705-730

Thygesen UH, Nilsson LAF, Andersen KH (2007) Eulerian techniques for individual-based models with additive components. J Mar Syst 67(1-2):179-188

Tilman D, Kareiva PM (1997) Spatial ecology: the role of space in population dynamics and interspecific interactions. Academic Press, San Diego

Turner JT (2004) The importance of small planktonic copepods and their roles in pelagic marine food webs. Zool Stud 43(2):255-266

Uchmański J, Grimm V (1996) Individual-based modelling in ecology: what makes the difference? TREE 11(10):437-441

Uttieri M, Zambianchi E (2012) On the fractal characterisation of zooplankton motion: applications and perspectives. In: Mitchell EW, Murray SR (ed) Classification and application of fractals: new research. Nova Science Publishers, Inc., New York, pp 113-129

Uttieri M, Mazzocchi MG, Nihongi A, Ribera d'Alcalà M, Strickler JR, Zambianchi E (2004) Lagrangian description of zooplankton swimming trajectories. J Plankton Res 26(1):99-105

Uttieri M, Zambianchi E, Strickler JR, Mazzocchi MG (2005) Fractal characterization of three-dimensional zooplankton swimming trajectories. Ecol Model 185(1):51-63

Uttieri M, Cianelli D, Strickler JR, Zambianchi E (2007a) On the relationship between fractal dimension and encounters in three-dimensional trajectories. J Theor Biol 247(3):480-491

Uttieri M, Nihongi A, Mazzocchi MG, Strickler JR, Zambianchi E (2007b) Pre-copulatory swimming behaviour of Leptodiaptomus ashlandi (Copepoda: Calanoida): a fractal approach. J Plankton Res 29(suppl 1):i17-i26

Uttieri M, Paffenhöfer G-A, Mazzocchi MG (2008) Prey capture in Clausocalanus furcatus (Copepoda: Calanoida). The role of swimming behaviour. Mar Biol 153(5):925-935

Uttieri M, Sabia L, Cianelli D, Strickler JR, Zambianchi E (2010) Lagrangian modelling of swimming behaviour and encounter success in co-occurring copepods: Clausocalanus furcatus vs. Oithona plumifera. J Mar Syst 81(1-2):112-121

Weissburg MJ, Doall MH, Yen J (1998) Following the invisible trail: kinematic analysis of mate-tracking in the copepod Temora longicornis. Phil Trans R Soc London B 353:701-712

Zambianchi E, Griffa A (1994) Effects of finite scales of turbulence on dispersion estimates. J Mar Res 52:129-148

Zar JH (1984) Biostatistical analysis. Prentice Hall, Englewood Cliffs, NJ

Ziarek JJ, Nihongi A, Nagai T, Uttieri M, Strickler JR (2011) Seasonal adaptations of Daphnia pulicaria swimming behaviour: the effect of water temperature. Hydrobiologia 661(1):317-327

Zollner PA, Lima SL (2005) Behavioral tradeoffs when dispersing across a patchy landscape. Oikos 108(2):219-230

\section{Submit your manuscript to a SpringerOpen ${ }^{\circ}$ journal and benefit from:}

- Convenient online submission

- Rigorous peer review

- Immediate publication on acceptance

- Open access: articles freely available online

- High visibility within the field

- Retaining the copyright to your article

Submit your next manuscript at $\gg$ springeropen.com 